\title{
INTER-SITE DYNASTIC RELATIONS \\ RECORDED ON A PLATE FROM HOLMUL, GUATEMALA
}

Dorie J. REents

University of Texas

A polychrome plate (fig. 1a) excavated by R. E. Merwin at Holmul in the early part of this century contains a long glyphic inscription which may record dynastic relationships between this site and $\mathrm{Na}$ ranjo, located some 30 kilometers south of Holmul. The plate (Peabody Museum \#c-5666, here designated H19) was one of five vessels accompanying an adult burial at Holmul in Building $\mathrm{F}$ of Group 1 (fig. 1b). The burial contained an individual of high status, indicated by the nature of the tomb itself and by the burial furniture. I suggest that the text painted on the plate refers to the interred individual and demonstrates dynastic ties between the two sites as the protagonist (i.e. the individual buried in this tomb) is recorded as being a descendant of Ruler 4 of Naranjo. Ruler 4 held the throne roughly between 9.17.0.0.0 and 9.17.13.0.0 (780-793 $\mathrm{AD})$ which would date the plate slightly later between. 9.17.13.0.0 and 9.19.0.0.0 (793-810 $\mathrm{AD})$.

The burial was found in Building $\mathrm{F}$ of Group I (fig. 1b). Merwin and Vaillant (1932:15) describe the building as having been constructed solely to serve as a burial mound. This is evidenced by the structure having only one building stage and its being intrusive into Group I. The funerary nature of Building $F$ is further revealed by the vaulted tomb having been built after the body was laid on the plastered floor.

The body was badly disintegrated when excavated, precluding any specific age or sex evaluation. It was wrapped in a textile shroud and later in a woven mat or petate, both of which were severely deteriorated when excavated. Two quarts of flint chips were scattered 
over the wrapped body. Five vessels were placed right side up in front of the body, containing variously the reddish brown dirt of the rotted textile, a jade bead (in H19), a limestone spindle whorl, and lime and plaster filling a bichrome cylinder. The elaborate construction of the tomb and preparation of the body plus the high quality of the accompanying pottery all attest to the elite nature of this burial. It is suggested below that this is the tomb of a Holmul ruler who may be the same as that recorded on the accompanying plate $\mathrm{H} 19$.

The text on the plate contains 31 glyphs (A through E-prime, written E-1) in a continuous sequence around the rim interior or the plate (fig. 2). Two other glyphs (F-1 1 and 2) are found on the bottom of the plate next to the figure occupying this area. ${ }^{1}$ The main text is a variant of the Primary Standard Sequence, or PSS, first identified by Michael Coe (1973). The following commentary will use Coe's terminology for the constituent PSS glyphs to avoid " $T$ "-number confusion.

The text (fig. 2) begins at A with the standard Initial Sign $A h$ nen (T229.617:126). What may be identified as the verbal phrase begins at B with the God N glyph (T1014a:88?) and is followed by the fire-quincunx compound (T1.248:585a). The youth head follows at D. Of note here are the two suffixes T181 and T542 (or T537?). Accepting the phonetic value of $n a$ for the latter, the two affixes may be read as na-kal following Stephen Houston's suggested reading for the standard youth head in the PSS (Houston n.d.). It should be further noted, however, that these two affixes are inverted from the expected order for the above proposed reading.

The next glyph (at E) is the inverted Ahau compound T1.534. When prefixed by T126, this glyph functions as a relationship glyph (c.f. the plate in Coe 1973:\#49). However, its function here on $\mathrm{H} 19$ is not clear.

1 The secondary text next to the main figure is composed of the day sing Ix and the Tikal emblem glyph. I do not believe, however, that the text refers to the Tikal lineage. Compare this text and scene with BNL 1374 (Coe 1978:\#14). Similar vertical texts are found next to the dancing figures. The third and fifth glyphs in each text on Princeton \#14 name the character sitting in the backrack of the dancing figure. The dancer on H19 has a jaguar seated in his backrack. And like BNL 1374, the two glyphs in the vertical text both refer to "jaguar", the daysing Ix being a depiction of the jaguar eye and the Tikal emblem glyph maisign being read as "balan" and by extension "balam" (Schele 1980, personal communication). These two glyphs may name the jaguar creature who sits in the backrack worn by the main figure on the bottom of the plate. 
The same youth head as at D follows the inverted Ahau glyph at $\mathrm{F}$. This second youth head is prefixed by T51 and lacks the suffixes T181:542 noted in the similar glyph at D. T51 is an affix which functions as a locative prefix and may have a similar function here. This youth head is characterized by the curved line composed of small circles in the upper rear of the head and is associated with texts from vessels painted in this same "Holmul style" (cf. the cylinder associated with this burial, Peabody Museum \#c-5668). Not precluding Houston's proposed reading above, this youth head resembles anthropomorphic versions of Ahau and here may be read as such (cf. the accession statement for Lord Cauac Sky on the Hieroglyphic Stairs at Copan who accedes to the throne as this head glyph, that is as a "lord" or "Ahau"). This second youth head is followed at $\mathrm{G}$ by the Muluc compound T168?:518s.? which is a common royal title known to substitute for Ahau or ah po in other inscriptions (cf. Piedras Negras).

The next three glyphs are PSS constituents, beginning with the fish T738:130 (at H). Coe's "rodent-bone" and "hand-monkey" compounds follow at I and J. These glyphs appear to function as nominal introducers in the PSS. As expected, an elaborate titular clause follows (from $\mathrm{K}$ through $\mathrm{Z}$ ), naming the protagonist of the inscription.

This long titular clause is unusual for the two different $K^{\prime}$ an glyphs at K-L and Y-Z. The first is T506, the daysing $K^{\prime} a n$. The glyph has two prefixes; that contiguous with the main sing is most likely a depiction of an axe such at that associated with the batab glyph. To the left of this affix is either T1 (phonetic $u$ ) or T25 (phonetic $c a$ ). The second $K^{\prime} a$ an glyph (at L, N and Z) is the PSS T507 "Spotted K'an" title but with different affixes than those listed by Coe. Here the prefix is $\mathrm{T} 177$ and the subfix is T23. Although this titular compound is found in other inscriptions (e.g. Palenque Palace Tablet at K8), its rendition on $\mathrm{H} 19$ may be particular to this region as the only other example with these specific affixes is found on a cylinder which names Naranjo royalty (Coe 1973:\#49; at I-prime 2).

The eroded glyph at $\mathrm{M}$ which intervenes between the two "spotted $K^{\prime} a n^{\prime}$ 'titles appears to be the tun glyph T548.130 with a superfix which may be the number "six" or T125 above a bar. However, the "serpent-segment" glyph of the PSS would not be out of place here, the main sign of which resembles the tun glyph T548. The 
indistinct nature of the read-on-orange paint of this glyph makes certain identification difficult.

The next two glyps (0-P) may record a captive taken by the protagonist. However, the "capture" glyph at 0 lacks the te affix usually associated with this compound and is here replaced by a bone. Further, the glyph seems to lack T25 (phonetic ca) which completes the "captive" glyph's reading of chu-ca. This glyph at 0 , then, may not be the "captive" glyph and instead may be some kind of title. However, if the glyph at 0 is a "captive" statement, the captive is named at $\mathrm{P}$ with a bat head T756 and a k'in (T646) or uinal (T521) glyph infixed over the mouth area. This glyph is not found in the inscriptions from Naranjo, however, and cannot be associated with any particular historical person in the Maya inscriptional corpus. This bat- $k^{\prime}$ in compound, rather than naming a captive, may be a title for the protagonist of the plate rather than a captive's name.

The name of the protagonist of the plate is found at Q-S. His personal name is composed of two glyphs. The first at $Q$ is the God K glyph T1030d, followed at R by a compound which is probably the personal name (fig. 3a). This name is composed of $\mathrm{T} 1$ followed by a human head with a solid band over the eyes and three dots resembling "death spots" on the cheek. This head most closely resembles T1044 (fig. 3f). However T1044 has a jawless skeletal saurian head spread over the top of the humanoid head whereas an open human hand (T670 inverted) replaces the saurian in the nominal here on H19. The person referred to by this nominal will be called Lord "Masked Face" until a more certain identification can be made.

This "masked face" nominal has been found in other inscriptions, all of which seem to be associated with the site of Naranjo. An eroded glyph on Stela 13 (at F11) (fig. 3c) may be the same nominal, here coming from a title phrase which names Naranjo Ruler 4. Another example is found on the codex-style cylinder BNL 1375 (fig. 3b) (Cioe 1973: \#47). In this latter example, the glyph appears in a name phrase for Naranjo Ruler 4 and is followed by the Naranjo emblem glyph. The third example comes from a polychrome bowl (fig 3d) (von Winning 1985: personal communication) whose painting style is similar to another bowl whose provenience may be Naranjo based on trace elemental analysis of the chemical composition of the bowl's ceramic paste (BNL 0540) (analyses run 
at Brookhaven National Laboratory by Ronald L. Bishop ${ }^{2}$ ). In sum, these three examples (fig. 3b,c,d) most closely resemble the nominal on H19. And all can be shown to have either a monument provenience, titular, or a chemical connection with the site of Naranjo.

This "masked face" glyph appears elsewhere in the Classic Period inscriptions and are here mentioned in an attempt to identify this head glyph. A similar "masked face" glyph is found in earlier inscriptions, including the Middle Classic Naranjo Altar 1 (at $\mathbf{M}$ ) (fig. 4e) which names Naranjo Ruler 1. This "masked face" is followed by a head variant of the "jester god" and would suggest that the phrase functions as a title or personal name. However, unlike that on $\mathrm{H} 19$, the open hand (T670 inverted) is not present in the "masked face" on Altar 1.

This "masked face" on Naranjo Altar 1 (fig. 4e) is very similar to a glyph found on the Palenque Temple of the Inscriptions Middle Panel (at L5) (fig. 3h) as a constant in a repeated clause whose reading is not known. Unlike the "masked face" glyphs discussed above, this glyph is prefixed by T204 and a "knot" pictograph. This compound is similar to one which is known be a "death" expression (Schele 1982:134,304) (fig. 3g). However, the glyphic environments of other examples of this compound (Schele 1982:176, 204, 268) do nct all reference "death". In short, the "masked face" on the Temple of the Inscriptions Middle Panel (fig. $3 \mathrm{~h}$ ) cannot be shown to be associated with the "death" compound nor can any of these compounds with "masked faces" be surely identified as the same as that on plate $\mathrm{H} 19$.

An Early Classic panel from Bonampak (fig. 4b) has a similar "masked face" glyph which names a local ruler. However comparison with this nominal's appearance on Yaxchilan Lintel 37 (fig. 4b) demonstrates that it is not the same as that on H19. Rather, the supposed "masked face" glyph on the Bonampak panel is a conflation of a "fish fin" pictograph and T1013.

Another "masked face" is found on Naranjo St. 38 (at B8) and

2 The Maya Polychrome Ceramics Project is a collaborative research program of the Research Laboratory, Boston Museum of Fine Arts, the Department of Chemistry, Brookhaven National Laboratory, and the Conservation Analytical Lab, Smithsonian Institution (all data is now filed at CAL). The purpose of the project is to provide trace elemental analyses, through neutron activation, of the ceramic pastes of the Late Classic polychrome pottery, to address questions of common sources of vessel production as well as the locations of these sources or workshops. For an in-depth discussion of the project, see Bishop et al., 1983. 
on a panel from El Peru (fig. 4a). In these two cases, the "masked face" glyph is prefixed to the emblem glyphs of these respective sites, seemingly substituting for the water-group prefix (T36). However, unlike the "masked face" on H19, the two examples do not have the open hand (T670 inverted) spread over the top of the head, and therefore may not be the same glyphs.

Other "masked face" glyphs are found in the Late Classic inscriptions. Lintel 3 of Temple IV at Tikal has five examples (fig. 4d) of a nominal compound whose main constituents are a "masked face" whose cheek is marked with a Cimi sign (or a "percentage" sign; both considered "death" signs). This head wears variously a skeletal saurian or an unknown glyphic element which resembles one half of an Akbal sign. The head closely resembles one found at Palenque in the Tablet of the Foliated Cross (at 011) and on the Palace Tablet (at E13) (fig. 4c). These latter two examples are found in what is clearly a deity list which begins with the wellknown Palenque Triad (Berlin 1962). Linda Schele (1981) has designated this "masked deity" as GVI, being the sixth deity mentioned in the list here in the Tablet of the Foliated Cross (N9-N12).

These "masked face" examples from Palenque and Tikal, then, name a deity whose nominal is composed of a "masked face" with a "death" sign on the cheek. Various glyphic elements are affixed to this head and infixed into its forehead, including a skeletal saurian and a sign similar to that for Akbal. In sum, this GVI nominal is composed of a constant feature (the "masked face") and a variable element (the infixed forehead features). Comparing these GVI names with the nominal on $\mathrm{H} 19$, all are composed of the same constant plus a variable element. The variable on $\mathrm{H} 19$ is the open hand T670 (inverted) rather than the skeletal saurian or the half Akbal sign found in the Palenque and Tikal examples.

In sum, the "masked face" glyph appears in diverse contexts in the Classic Period inscriptions. It is found in (1) a "death" expression, (2) in other verbal phrases which are not "death" expressions, (3) substituting for the water group preffix of emblem glyphs, and (4) as a constituent of the name of the deity GVI. Due to the affix substitutions and the variable glyphic syntactic environments, it is not possible at this time to identify a semantic domain for this "masked face" on H19. The strongest possibility would be that the "masked face" glyph refers to the deity GVI as it was a common practice during the Classic Period to include in royal nominal the names of deities. 
The presence of the Naranjo emblem glyph at $\mathrm{S}$ (fig. 2) records Lord "Masked Face's" lineage affiliation. Further evidence of his lineage is the glyph at $\mathrm{T}$ which is surely the head variant of the Zac-Chuen title, an integral part of the nominals of Naranjo Rulers 1 through 5. To my knowledge, this is the only example of an anthropomorphic version of this Zac-Chuen title.

The text on H19 continues with more titles for lord "Masked Face" (U-Z). That at U is a 6-ah po Ahau compound followed by an unusual anthropomorphic head glyph at V. The two glyphs at $\mathrm{W}-\mathrm{X}$ are found in pottery texts associated with Naranjo rulers (fig. 5a-e). This nominal at $\mathrm{W}$ begins with the male pronominal preffix ah T12. The main sign is a saurian head with a zoomorphic head below its jaw. This lower head is very similar to those of the daysign $E b$ or Cimi, although the skeletal features usually associated with these glyphs are not clear here on the plate. Similarities are also noted with the geometric version of the day Men. In the absence of certain identification, the compound will be tentatively referred to as the "Ah Cimi" title. The following glyph (X) is the head variant of the royal appellative Ma-k'ina which includes the head of the sun god T1010.

These two titular glyphs "Ah Cimi-Ma k'ina" are also found in the texts on four unprovenienced vessels (fig. $5 \mathrm{~b}-\mathrm{e}$ ), three of whose affiliation with Naranjo can be demonstrated through glyphic and chemical analyses. The first cylinder (fig. 5c), referred to as BNL 1374 after its sample number in the chemical archive at the Smithsonian Institution, is painted in the same "Holmul style" as is H19. Although the title on BNL 1374 is not clear in the published version, photograps of the vessel following removal of the surface dirt reveals the glyph at $\mathrm{K}$ to be the same "Ah Cimi" title. The uneroded Ma k'ina glyph here on BNL 1374 (at L) provides the identification for the eroded glyph at $\mathrm{X}$ on H19. The inscription on BNL 1374 (see Coe 1978) is nearly identical to that on another elaborately painted vessel Grolier \#49 (Coe 1973) (here fig. 5b). These two cylinders were probably painted by the same artists. The titular glyphs at K-L on these latter two vessels are the same at those on $\mathrm{H} 19$ (at W-X) (cf. fig. 5a,b,c).

Previously, the only provenience evidence for the "Holmul style" BNL 1374 cylinder was its purported grave lot association with a codex-style cylinder BNL 1375 (Coe 1973:\#47). The text on BNL 1375 (fig. 5f) lists two known Naranjo rulers (Ruler 4 Lord "Flint Face" and Lady "Star-Shell"). Lord "Flint Face" is also mentioned 
in the parentage statement on $\mathrm{H} 19$ with the same glyphs as those in his name phrase on BNL 1375 (fig. 5f). The nominal phrase on BNL 1375 also includes the same two title glyphs "A Cimi-Ma k'ina" as found on H19. These glyphic equivalencies strengthen the suggested Naranjo association for both BNL 1374 and 1375, and by extension for the protagonist of plate H19.

It should be mentioned that the chemical profiles of BNL 1374 and 1375 are nearly the same. These profiles are generated through trace elemental analyses which chemically characterize the constituent clays, or pastes, of these vessels. This chemical equivalency of BNL 1374 and 1375 suggests that they were made from the same preparation of clay (Ronald Bishop 1984: personal communication). Further, the chemical profile matches those of potsherds from Naranjo (currently in the Museo Nacional de Guatemala). The chemical data, then, imply that BNL 1374 and 1375 were created in a workshop in the vicinity of Naranjo.

The chemical profile of $\mathrm{H} 19$ does not closely resemble that for BNL 1374 and 1375. Rather, the H19 profile lies "between" those associated with Naranjo and those of sherds and whole vessels excavated at nearby Holmul. Plate $\mathrm{H} 19$, then, was probably made in a different workshop than that responsible for 1374 and 1375. Yet the somewhat similar chemical profiles of these three samples suggest that both workshops were located in same general vicinity, near the archaeological sites of Naranjo and Holmul respectively.

Lord "Masked Face's" Naranjo association, then, is established glyphically, stylistically, and chemically. The Naranjo emblem glyph and Zac-Chuen title (at S and T) on H19 explicitly indicate his lineage. Further, the God $\mathrm{K}$ glyph in his name is also a constituent of Late Classic Naranjo rulers' names (cf. Ruler 5 "Shield-God K" and Ruler 6 "18 Imix-God K"). The "masked face" nominal is very similar to a glyph found on various Naranjo monuments (Altar 1, Stela 13, Stela 38, BNL 1375). And the two titles at $\mathrm{W}$ and $\mathrm{X}$, "Ah Cimi-Ma k'ina", appear together on painted vessel which are certainly associated with Late Classic Naranjo rulers (BNL 1374, 1375). In case there were any question as to the lineage affiliation of Lord "Masked Face", the H19 text ends by stating his parentage (fig. 2; A-1 through E-1). Lord "Masked Face" is recorded as the direct descendent ("child of father" glyph at A-1) of Lord "Flint Face" (Ruler 4) of Naranjo. Lastly, plate H19 is painted in the "Holmul style" which was created during the Late Classic Period in the general Holmul-Naranjo vicinity (Reents n.d.). The chemical 
profiles of the clay paste of $\mathrm{H} 19$ and of BNL 1374 and 1375 are similar to those of sherds from Naranjo and Holmul.

In sum, the inscription on Holmul plate H19 is note worthy for its historical-genealogical content. The various nominals and titles can be consistently tied with the historical inscriptions from $\mathrm{Na}$ ranjo. The $\mathrm{H} 19$ text takes great pains to insure that the reader understands that the protagonist lord "Masked Face" is of the ruling lineage of Naranjo. But precisely who is this Lord "Masked Face"?

We know that Lord "Masked Face" is a descendent of Naranjo Ruler 4 Lord "Flint Face". ${ }^{3}$ As such, he probablv represents the next generation after Ruler 4, which would make him contemporaneous with Naranjo Ruler 5 (who reigned between 9.17.13.0.0.9.19.0.3.0). This chronological placement is corroborated by George Vaillant's dating of the Holmul tomb who placed this pottery style and the Holmul burial "... closer to 10.0.0.0.0 than 9.15.0.0.0" (Merwin and Vaillant 1932:81).

As both of these contemporaries (God K-Lord "Masked Face" and Ruler 5 "Shield-God K") carry the Naranjo emblem glyph and contain the God $\mathrm{K}$ glyph as parth of their names, it is possible that God K-Lord "Masked Face" is the same as Naranjo Ruler 5 "ShieldGod K". Assuming that the presence of this plate in an elite burial at Holmul which details the Naranjo ruling lineage indicates some type of hegemony of this lineage at Holmul, and that the two nominals refer to the same person, one could suggest that the same person is ruling the two sites simultaneously.

There is evidence in the inscriptions from Naranjo and other sites of a single ruler controlling more than one site. During the Middle Clasic, Lord "K'an II" of Caracol takes control of Naranjo through non-peaceful means and rules the two sites simultaneously (Stone, Reents, and Coffman in press). "God K-Sky-Ma k'ina", a ruler of Aguateca (of the Petexbatun polity), also exercise hegemony over Seibal after 9.1513.13.0 (Kevin Johnson, personal communication). ${ }^{4}$ Therefore, there is precedence for Naranjo Ruler 5

${ }^{3}$ Comparisons of the nominal phrases on Naranjo Stelae 19 (C5) and 33 (B4) with those on BNL 1375 strongly suggest that the "Flint Face" glyph is an alternate nominal for Ruler 4 ("Smoking Batab"). This identification is strengthened by the "Flint Face" title on BNL 1375 (fig. 5f).

4 I wish to thank Kevin Johnston for freely sharing his data on the Petextbatun lineage and for stimulating discussions of the interpretation of H19 which were central to consolidation my thoughts on this plate.

Mimi Crossley's recent re-evaluation of the Naranjo dynasty has been most helpful in comparing the many titles found on this plate. 
to be concurrently ruling Holmul. However, if we assume that the burial at Holmul is that of the person mentioned on the plate (i.e. Naranjo Ruler 5), it would be unusual for him to be burięd here rather than at Naranjo.

This leaves us with two alternative possibilities. First, it is possible that the person buried with this plate is not the same as that named on the plate. It is a general assumption among Mayanists that vessels with glyphic inscriptions found in tombs refer to the interred individual. However, contrary data do exist. For example, Burial 72 from Tikal (Coggins 1975) contains the skeleton of an adult female. The round-sided bowl included in the burial furniture records the name and titles of Naranjo Ruler 1. Clearly the woman in the burial at Tikal is not Naranjo Ruler 1 who certainly was male. Therefore, if the person buried at Holmul is not named on the plate, the plate's presence in the burial would still suggest strong ties between the two sites, ties which we can assume are lineagebased.

The second possibility is that God K-Lord "Masked Face" and Naranjo Ruler 5 "Shield-God K" are not the same person even though they both carry the Naranjo emblem glyph. Rather, these two may be contemporaries from the same lineage (both being descended from Naranjo Ruler 4 Lord "Flint Face"), with each ruling a different site. Although it has been assumed that only one ruler can carry a site's emblem glyph at a time due to the nature of Maya accession politics, these two individuals simultaneously would carry the Naranjo emblem glyph because they were ruling at different places. If so, one could suggest that the person in the Holmul burial and who is mentioned on $\mathrm{H} 19$ is a lesser royal individual with the same dynastic affiliation as Naranjo Ruler 5.

Looking again to the Petexbatun region, a similar situation is en-

I also wish to acknowledge the extensive help of Barbara and Justin Kerr in providing photographs which contained critical data.

I would like to thank Clemency Coggins for bringing to my attention the 'posse of 'masked men'" on Tikal Temple IV Lintel 3.

To Ms. Una MacDowell of the Peabody Museum go my expressed gratitude for the generosity in providing unlimited access to $\mathrm{H} 19$ at the Peabody Museum. I wish to also thank Mr. Dan Jones of the Peabody Museum whose extensive photographic knowledge was instrumental in my acquiring excellent photographs of $\mathrm{H} 19$ which were central to drawing the plate's glyphic text.

Without the generous assistance of each of these individuals, this paper would not have been possible. The author, however, takes all responsibilities for the current form of the paper. 
countered at Aguateca. Lord "Sky-Ma k'ina Ahpo-Turtle Shell" of Aguateca (Stela 5) carries the Petexbatun emblem glyph at the same time as does Lord "Flint Sky-God K" of Dos Pilas. Lord "Sky-Ma k'ina Ahpo-Turtle Shell" of Aguateca is in some capacity politically subordinate to Lord "Flint Sky-God K" of Dos Pilas, although both evidently are rulers from the same royal lineage (Kevin Johnston in press).

In light of the above, I suggest that Lord "Masked Face" is a descendent of Naranjo Ruler 4 (Lord "Flint Face" or "Smoking Batab") and is a contemporary or Ruler 5 . He may be a secondary member of the Naranjo royal dynasty such as a second son or nephew of Ruler 4. The inscription on $\mathrm{H} 19$ takes great pains in utilizing numerous titles found in the Naranjo inscriptions from 9.8.0.0.0 through 9.18.0.0.0. This plethora of titles suggests a strong desire to make explicit the relationship of the protagonist with the Naranjo lineage, thus consolidating a possibly nebulous or secondary association. His presence at Holmul, then, would represent a physical extension of Naranjo's political power in the region. Many war events are found in Naranjo's Late Classic inscriptions spanning three rulers' reigns (Ruler 3 through Ruler 5) (e.g. Stelae 30, 13 12 , and 35). Although there is no explicit evidence, one of these could possibly record an event during which Naranjo gains hegemony over Holmul, placing one of its dynastic members in control at Holmul.

Two cautionary notes are sounded here. First, there are no monuments or other known texts from Holmul and thus we have no records of any local ruling lineage and its associated names. And conversely, none of the Naranjo inscriptions can be demonstrated to be referring to Holmul. Secondly, this political reconstruction is predicated on the assumption that the Holmul burial is that of a ruler of the site and is the person named on the plate. This identification in based on circumstantial evidence and on comparison with various inscriptional examples from the Petexbatun region. This reconstruction, then, is offered only as a working hypothesis and is subject to suggestions from other epigraphers.

Although the above is a hypothetical reconstruction of a small portion of Late Classic Maya history, the inscription on plate H19 does attest to socio-political ties between Holmul and Naranjo, regardless of the identification of the skeletal remains in the burial and of the person mentioned in the glyphic text on H19. If the text refers to the entombed individual, the apparearance of this 
plate in what appears to be an elite burial suggests that the individual in the tomb held a powerful position at Holmul. The numerous titles and emblem glyph found in the nominal phrases on the plate indicate lineage ties with the Naranjo ruling dynasty. From other Middle and Late Classic inscriptions we know that lineages were extending their influence over other. sites through both peaceful and non-peaceful means, placing lineage members in control of these sites. This burial at Holmul and its accompanying plate may document a similar scenario for Holmul and Naranjo.

\section{REFERENCES CITED}

Benson, BetTy, ED.

1980 Third Mesa Redonda de Palenque, Part 1, Pre-Columbian Art Research Institute, San Francisco.

Bishop, Ronald L., G. Harbottle, D. Reents and L. vanZelist

1983 Compositional Attribution of Non-Proveniented Maya Polychrome Vessels, Fifth International Seminar on Applications of Science in Examination of Works of Art, Boston Museum of Fine Arts.

Coggins, Glemency

1975 Painting and Drawing Styles at Tikal, Doctoral dissertation, Harvard University.

Coe, Mighael

1973 The Maya Scribe and His World, The Grolier Club, New York.

1978 Lords of the Underworld, Princeton Univ. Press.

Houston, Stephen

n.d. Unpublished ms. discussing various glyphs in the PSS. Donot cite without permission of Mr. Houston, Dept. or Anthropology, Yale University, New Haven, Connecticut.

JoHNSTON, KEvin

in press "Maya Dynastic Territorial Expansion: Glyphic Evidence From Classic Centers of the Pasion River, Guatemala", to be published in the Papers of the Quinta Mesa Redonda de Palenque.

Merwin, Raymond and George Vaillant

1932 The Ruins of Holmul, Memoirs of the Peabody Museum, Vol. III, no. 2, Cambridge, Mass.

Reents, Dorie J.

n.d. The Late Classic Maya Holmul Style Polychrome Pottery, Doctoral dissertation, Department of Art, University of Texas at Austin (1985).

Schele, Linda

1981,1983 Notebook for the Maya Hieroglyphic Workshop, University of Texas, Austin.

Stone, ANDREa

in press "Genealogical Documentation of the Middle Classic Dinasty of Caracol, El Cayo, Belize", in Papers of the Quarta Mesa Redonda de Palenque, Pre-Columbian Research Institute, San Francisco. 


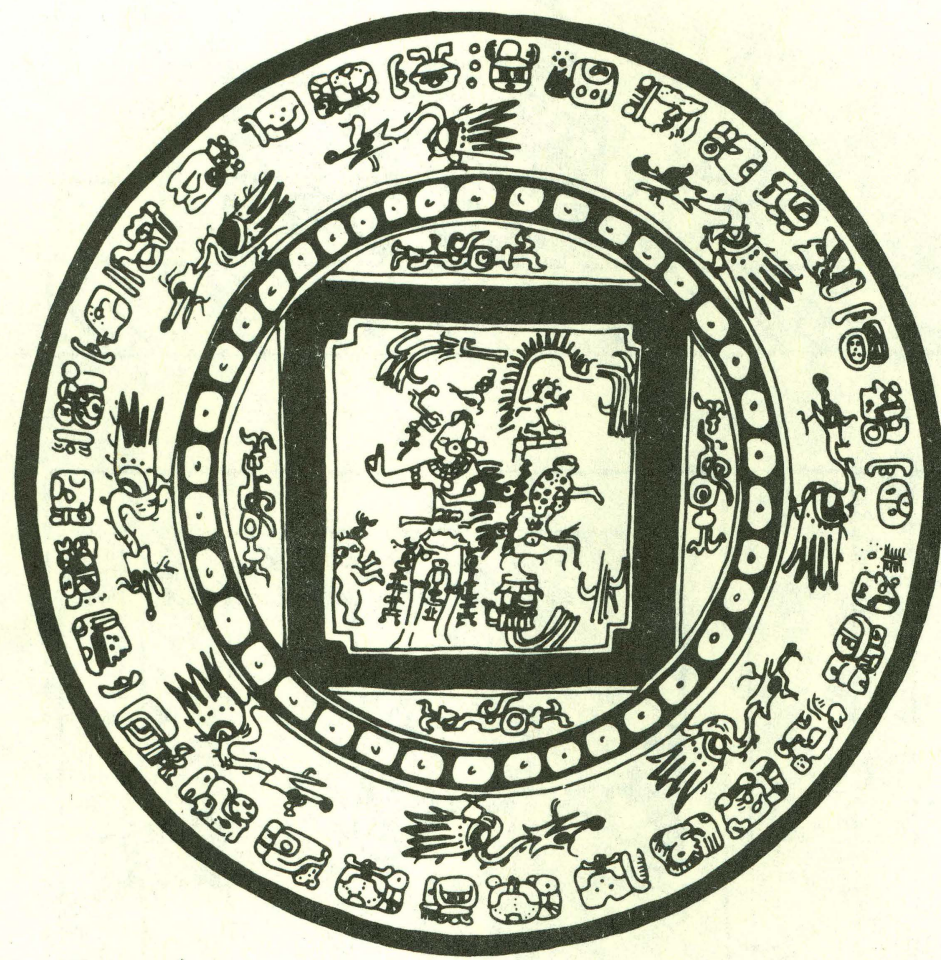

Figura 1

a. Drawing of Plate H19 (by Dorie Reents, after Vaillant 1935:93). 

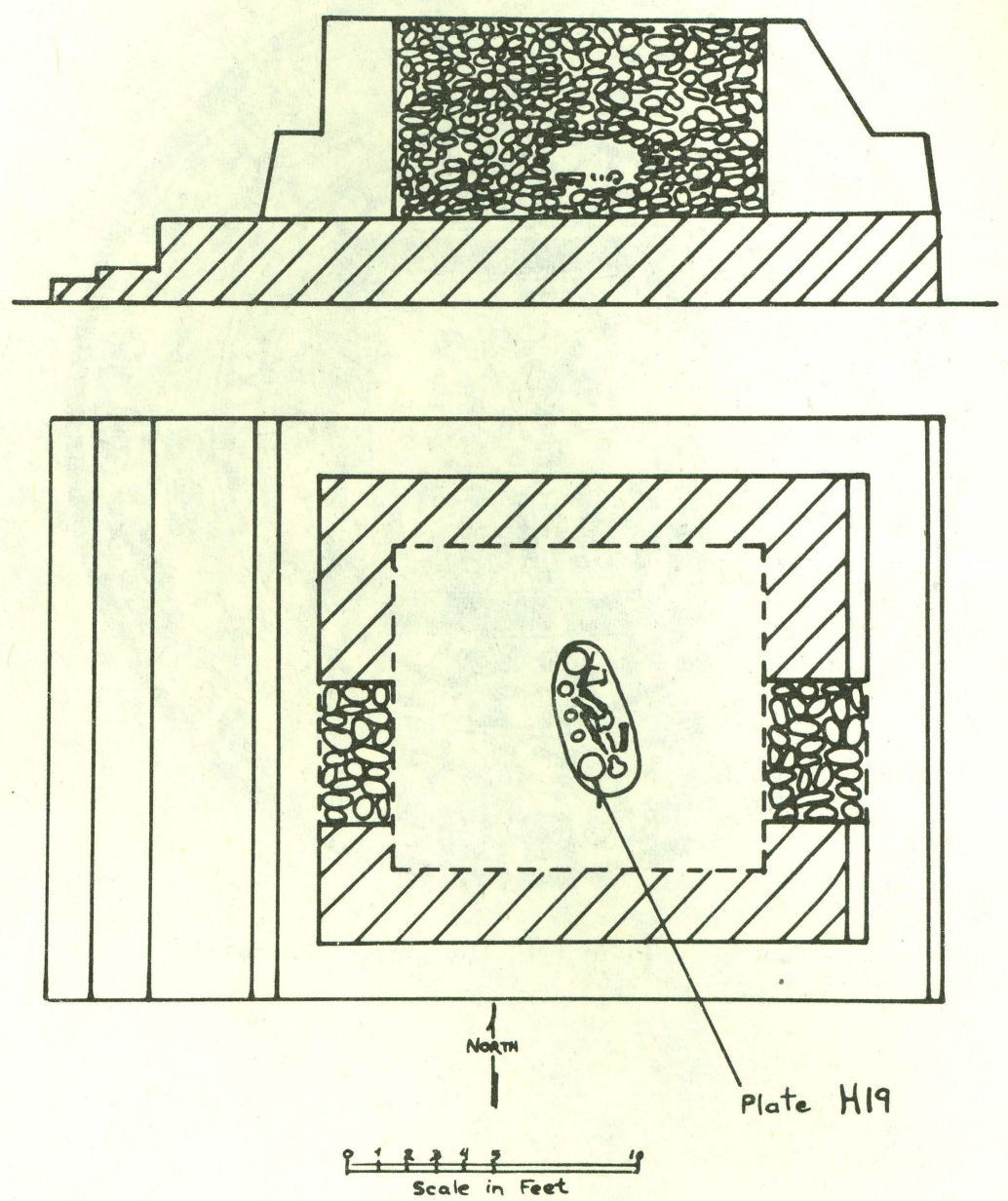

b. Plan of the burial in Building F, Group 1 at Holmul (by Dorie Reents, after Merwin and Vaillant 1932:14). 


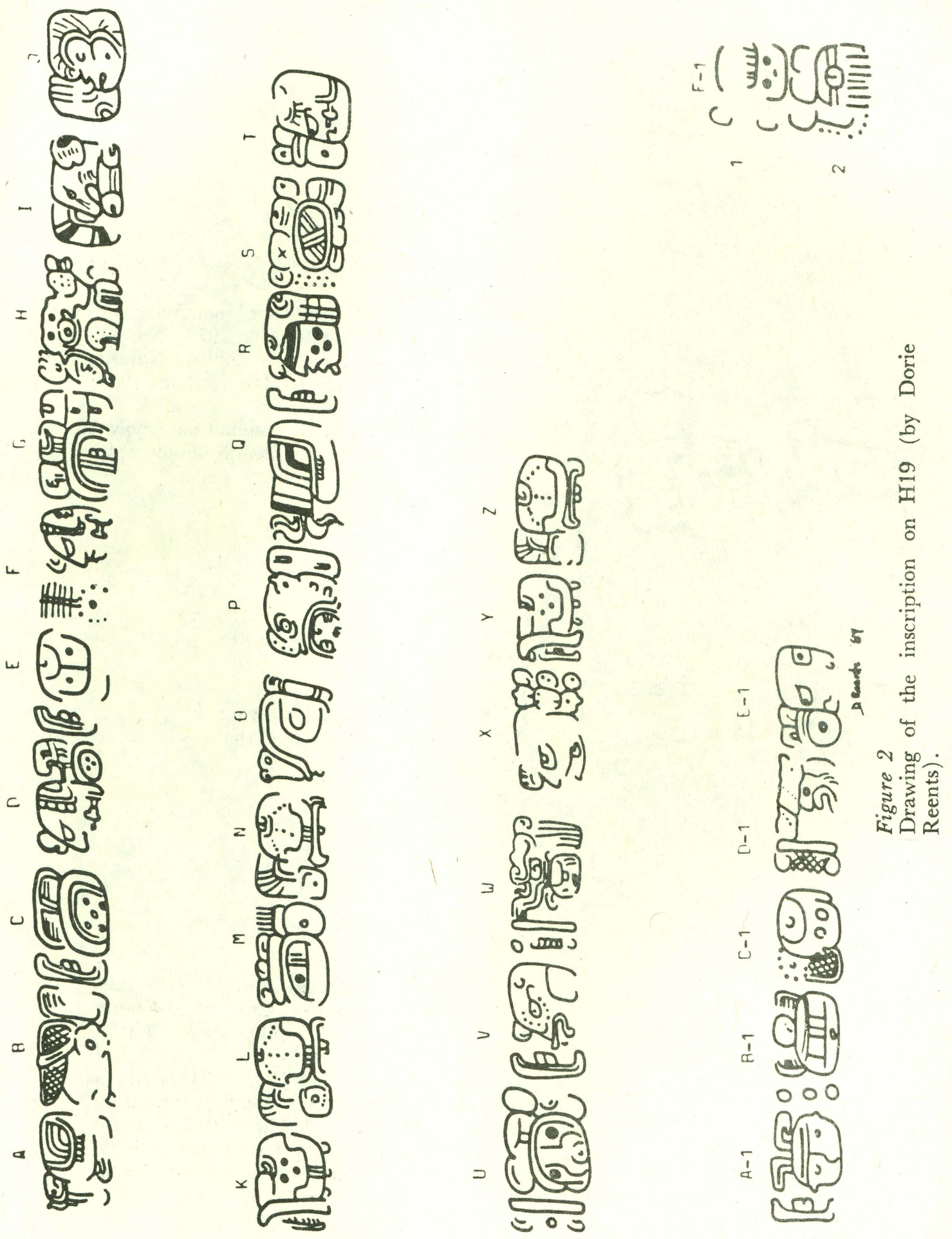



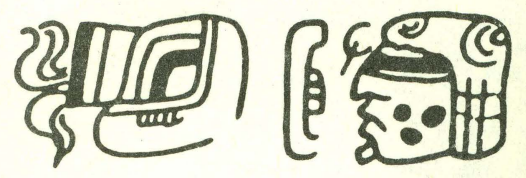

a

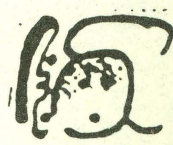

b

Figure 3

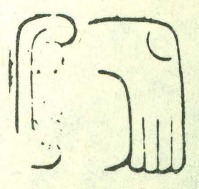

a. God K-Lord "Masked Face" on H19 (by Dorie Reents).

C

b. A similar "Masked Face" nominal on cylinder BNL 1375 (after Coe 1973: No. 47).

c. The "Masked Face" nominal on Naranio Stela 13 (at F11) (after Ian Graham 1978).

d. The "Masked Face" nominal on a polychrome bowl (by Torge Euan from a photograph c Justin Kerr 1930).

d
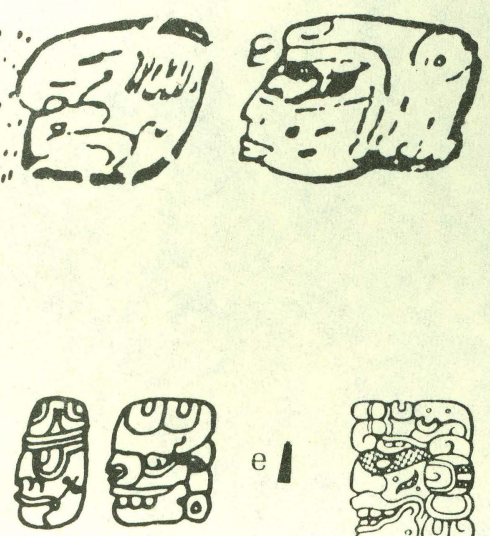

e

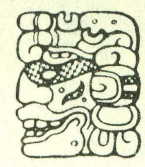
e. T1042 (Thompson 1962).
f. T1042 (Thompson 1962)

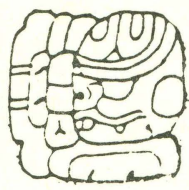

g. T1042 in the "death" expression; here from the Tablet of the Foliated Cross at Palenque where it functions as an alternative "birth" expression. (by Linda Schele).

h. The "Masked Face" glyph (T1042?) in a compound similar to the "death" expression above, yet which does not have this meaning here in the Temple of the Inscriptions Middle Panel (at L5) from Palenque. (by Linda Schele). 

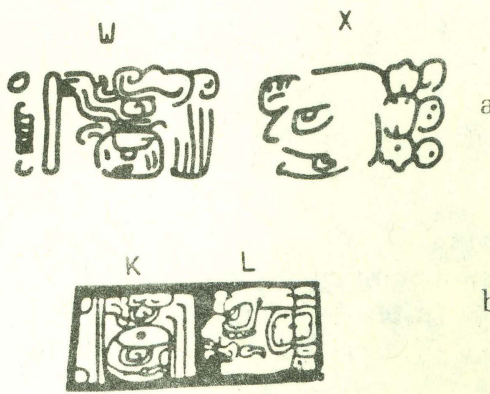

b

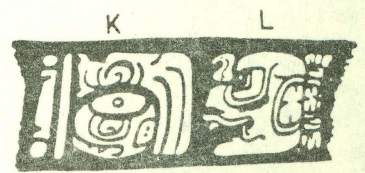

\section{Figure 5}

a. saurian head and sun god-Ma K'ina title on plate H19 (by Dorie Reents).

b. saurian head and sun dog-Ma K'ina title on Grolier No. 49 (after Coe 1973: No. 49).

c. saurian head and sun god-Ma K'ina title on BNL 1374 (after Coe 1978: No. 14).

d. saurian head and sun god-Ma K'ina title on a codex style cylinder (after Cioe 1978: No. 6).

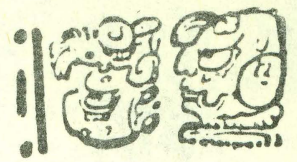

e. saurian head and sun god-Ma K'ina title on polychrome cylinder (after Coe 1978: No. 20, and photograph c Justin Kerr 1977).

f. Lord "Flint Face" on plate H19 (the parentage statement).

Lord "Flint Face" on BNL 1375 (by Dorie Reents after Coe 1973: No. 47).

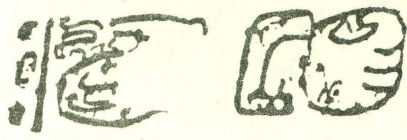

e

A-1 $\quad$ B-1 $\quad[-1$

D-1

$E-1$

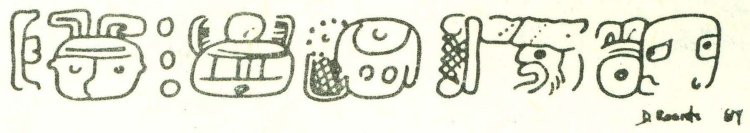

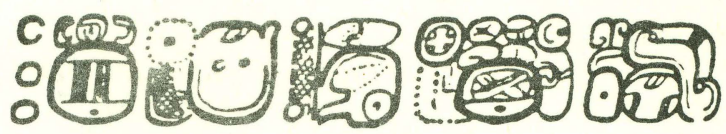

s

T

U

V

W 